\title{
The role of anticipation of post-session feeding in increasing resistance to punishment'
}

MOHAMMAD AKHTAR ${ }^{2}$ and ELIZABETH K. BOND, ${ }^{3}$ Marquette University, Milwaukee, Wis.

A previous study had obtained in two experimental conditions an extremely heightened resistance to electric shocks of an aversive intensity. Throughout a month of testing, Ss delivered to themselves 20 shocks per day via bar-pressing. Testing was continued even beyond one month in the present study, which investigated the role of anticipation of post-session feeding as an explanation of the increasing resistance. When rats were detained in a Skinner box or in their home cages before feeding, their performance curves stopped rising and, in some cases, underwent a decline.

A previous study (Akhtar 1967) showed an increasing resistance to test punishments as a result of counter-conditioning. The performance of two groups designated as IP-17 and IPf was striking. The IP-17 group was trained for 17 days with a gradually increasing ratio of interspersed punishments with rewards and the IPf group was trained for seven days with a fixed ratio of punishments interspersed among rewards. In spite of the variation in their training procedures, the two groups were very similar in daily test performance on 20 shocked trials unaccompanied by any food reward. Only these two groups (out of six experimental conditions) continued pressing the lever for shocks only, throughout the four-week long testing phase of the experiment. Out of a total of 12 each, eight Ss from IP-17 and 10 Ss from IPf were inextinguishable and responded without showing any diminution; instead they showed a gradual improvement in response rate. The senior investigator suspected that the feeding given immediately after every experimental test and $\mathrm{Ss}^{\prime}$ anticipation of such feeding was the factor responsible for the gradual improvement in their test performance. In order to assess the effect of anticipation of feeding, the present investigation subjected animals to a detention period before they were given their daily rations. Ss were detained in one of two situations: in a Skinner box or in their home cages. Some of the Ss used in the previous study were continued in the experiment for an additional month for the purposes of the present study.

\section{Experimental Design}

\section{METHOD}

The experimental treatment consisted of three phases: (A) detention in a Skinner box; (B) detention removed, that is, immediate feeding; and (C) detention in home cages.

Apparatus and Subjects

Many of the details of the method are reported in the previous study (Akhtar 1967).

Eight Ss from IP-17 had continued in the experiment (through failure to reach criterion for elimination during testing), and all eight were taken through the three phased treatment. Ten Ss from IPf, however, were randomly divided into two groups, detained (D) and undetained (UD). Only the D group went through all three phases of the experiment; the Ss in the UD group were fed immediately after each experimental test session, except near the end when they were detained in their home cages.

Procedure

Tests with 20 shocked bar presses were continued every day as before; at the end of each bar-pressing session, however, Ss were now either detained for $1 / 2 \mathrm{~h}$ or were fed immediately. Feeding consisted of placing approximately $15 \mathrm{~g}$ of Purina chow into the home cages; this was the amount of food necessary to maintain the rats at $80 \%$ of their initial ad lib weights.

IP-17: Eight Ss had continued in the test phase for $\mathbf{3 0}$ days as reported in the previous study, after which they were treated as follows:

A. Detained in Skinner box: Days 31-47. After the experimental session, all the $S$ s were left for $1 / 2 h$ in another Skinner box identical to the one used for experimental sessions but placed in another room.

B. Detention removed: Days 48-57. Immediately after the experimental session all Ss were fed in their home cages.
C. Detained in home cages: Days 58-65. All Ss were placed in their home cages in the animal room but were not fed until $1 / 2 \mathrm{~h}$ had elapsed.

IPf: 10 Ss had been bar pressing for 24 days, after which they were treated as follows:

A. Detained in Skinner box: Days 25-30. Only five Ss were detained (D) in the manner described above, while five continued undetained (UD).

B. Detention removed: Days 31-38. The five D Ss, as well as the five UD Ss, were fed immediately.

C. Detained in home cages: Days 39-48. The five D Ss were now detained in their home cages. But, since for them the effects of this detention might have been confounded with the effects of their previous detention in the Skinner box, the five UD Ss were detained as well, for the first time, in order to isolate the effect of home-cage detention.

\section{RESULTS}

Rate of bar pressing was the measure used to compare the effects of detention vs no detention. Mean rates of responding per minute for IP-17 and IPf are shown in Fig. 1 and 2, respectively.

Intra-S comparisons were assessed with the Wilcoxon Matched-Pairs Test and comparisons between independent groups were made with the Mann-Whitney U Test (Siegel, 1956). Differences in rate of bar-pressing during the three phases and the probabilities of these differences are shown in Table 1.

Both intra-S comparisons (for IP-17 and IPf) and inter-S comparisons (for D vs UD) yield the following results: (1) Ss show a significant gradual improvement in test performance before detention. (2) Detention in a Skinner box causes the IPf performance curve to level off and leads to a further significant decline in the performance of IP-17. (3) Removal of detention reinstates the increasing response rate of IP-17; while in IPf removal shows a similar, but nonsignificant, effect due probably to the lessened effectiveness of the preceding detention. (4) Detention in home cages likewise reduces the tendency to increase response rate in IP-17 and in IPf (UD); only in the later group, this effect is isolated without confounding it with previous detention. DISCUSSION

It was amply clear that detention in both a Skinner box or a home cage was effective. The effects of detention and its removal, however, were not as clear-cut in IPf (D) as in IP-17. This may be due to a larger $N$ and longer duration of detention in IP-17 (16 days in IP-17 vs 6 days in IPf). Still another reason appears to be that detention in IPf (D) was introduced earlier, i.e., after Day 25 (in contrast to Day 31 of test-plus 10 additional days of training for IP-17) when the development of anticipation of feeding was possibly weaker and its check was not of as much consequence. This supposition is based on consideration of IPf (UD) with the same size of $N$ as in IPf (D), but who were detained in their home cages after Day 39; detention was maintained for only five days (Days 40-44), yet it significantly reduced their performance.

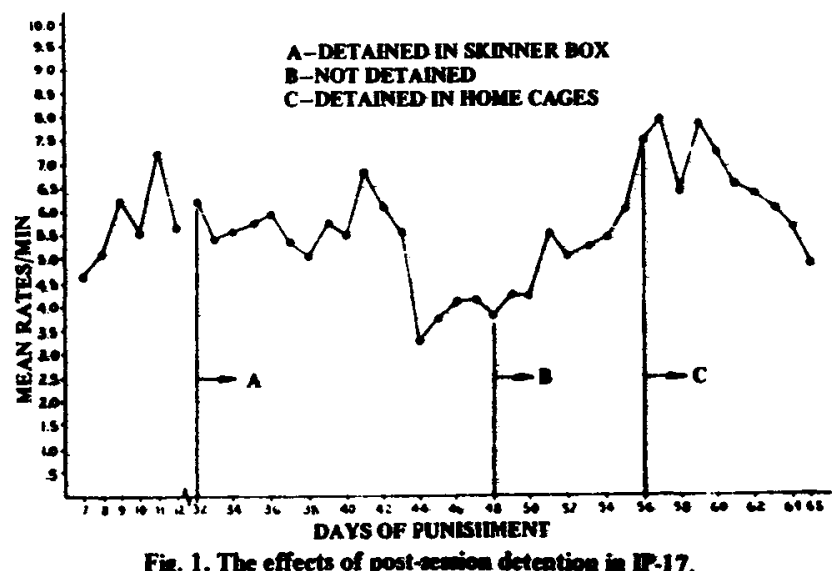

Fic. 1. The effects of post-revion detention in P-17. 
Table 1

A. Intra-S Comparisons in IP-17 and IPf

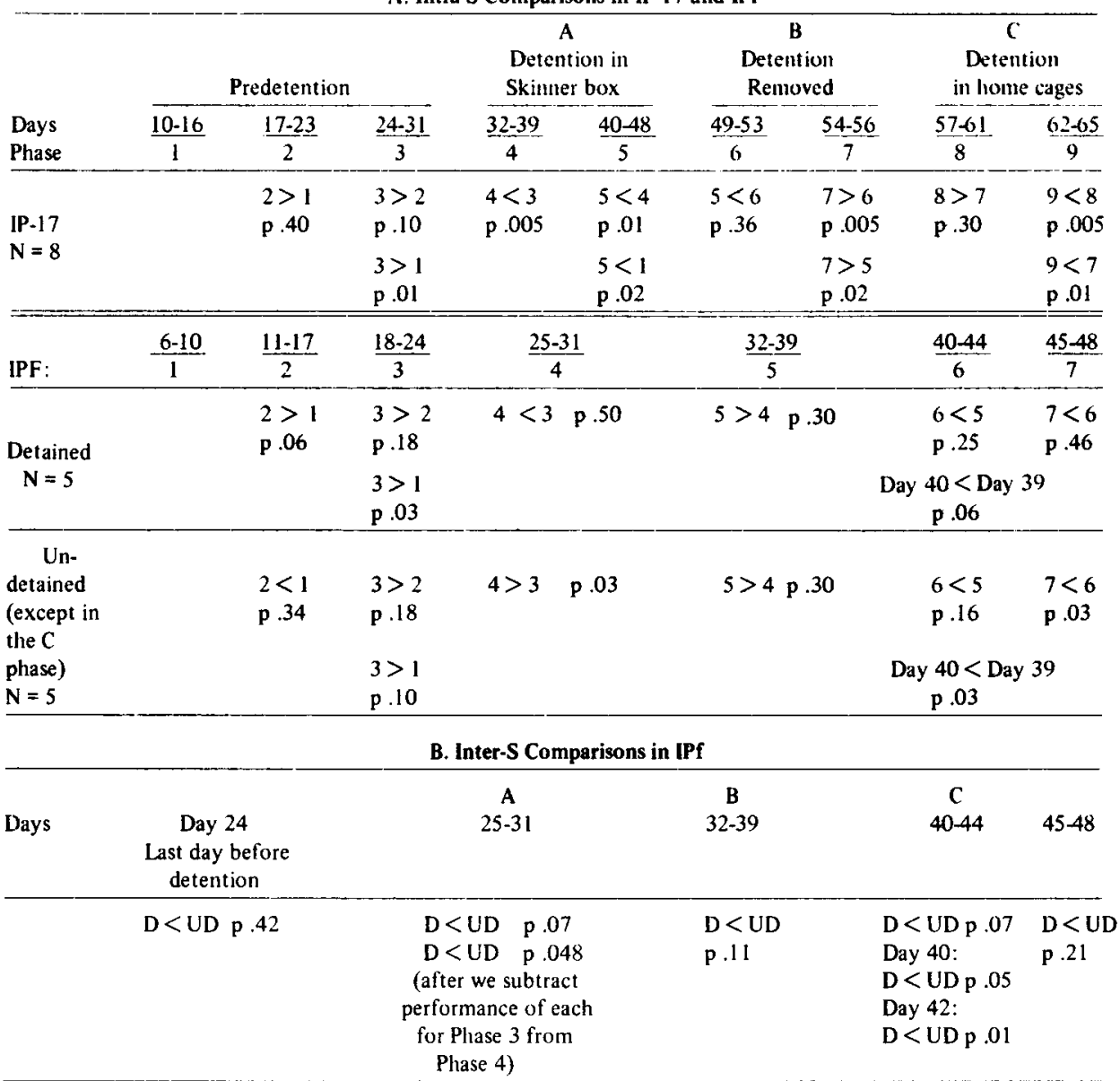

Similarly. it appears that anticipation of feeding may have been an effective variable arising only toward the end of the experiment. It alone, however, cannot adequately explain the earlicr resistance to shocks shown by the IP-17 and the IPf groups, since other groups were also fed immediately after their testing sessions. and yet they did not develop such resistance. This prevents us from treating the high resistance (found in the previous study) merely as an artifact of immediate feeding. It would appear, then, that a tendency to increase response rate in spite of shock is encouraged by inmediate post-session feeding only after considerable resistance to shocks has been developed earlier.

There is a serious lack of studies on the effects of immediate vs delayed feeding. In view of the present findings. however, the fact

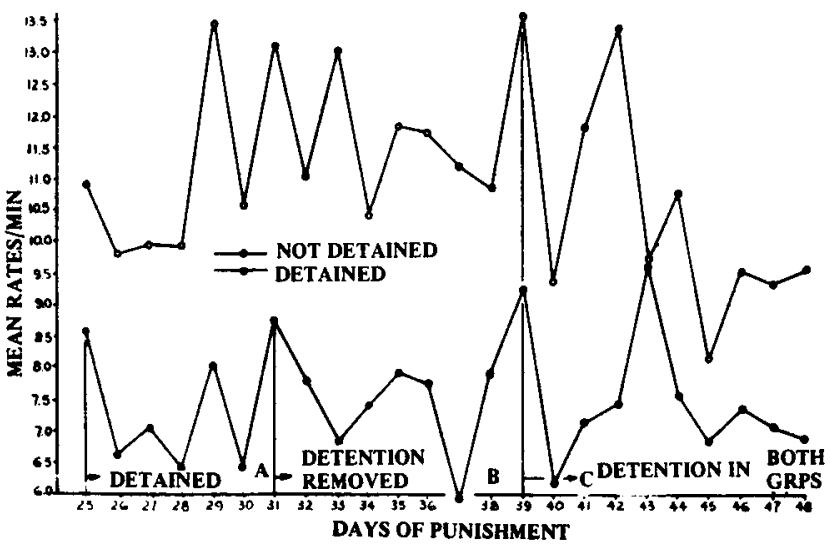

Fig. 2. The effects of post-session detention in IPf. that immediate post-session feeding is the usual procedure in animal experiments should introduce the possibility of a reinterpretation of data in a number of experiments. This would be of particular concern in studies utilizing prolonged periods of testing under the absence of reward. Studies with runway (e.g. Weinstock, 1958: Goodrich, 1959) seem to have used a delay in post-session feeding more often than studies with free operant responses (e.g., Zimmerman. 1959). Zinmerman demonstrated durable effects of secondary reinforcement and obtained bar-press responses which persisted for $141 \frac{1}{2} \mathrm{~h}$ sessions under the absence of food. But he failed to indicate anything about the post-session feeding, if it was delayed or not. An immediate post-session feeding in his study might have possibly contributed to sustained responses.

\section{REFERENCES}

AKHTAR, M. Increased resistance to punishment as a function of counterconditioning. Journal of Comparative \& Physiological Psychology, $1967,64,268-272$.

GOODRICH, K. P. Performance in different segments. Journal of Experimental Psychology, 1959, 57, 57-63.

SIEGEL, S. Nonparametric statistics. New York: McGraw-Hill, 1956.

WEINSTOCK, S. Acquisition and extinction of a partially reinforced running response at a 24-hour intertrial interval. Journal of Experimental Psychology, 1958, 151-158.

ZIMMERMAN, D. W. Sustained performance in rats based on secondary reinforcement. Journal of Comparative \& Physiological Psychology, 1959, $52,353-358$.

\section{NOTES}

1. The present research was partially supported by Grant MH-11456 from the United States Public Health Service.

2. Now at University of Karachi, Department of Psychology, Karachi 32, Pakistan.

3. Now at National Institute of Mental Health. 